\title{
Effects of an antenatal dietary intervention in overweight and obese women on 6 month infant outcomes: follow-up from the LIMIT randomised trial
}

\author{
Jodie M Dodd $\mathbb{D}^{1,2} \cdot$ Andrew J McPhee $^{3} \cdot{\text { Andrea R Deussen } \mathbb{D}^{1} \cdot \text { Jennie Louise }}^{4} \cdot$ Lisa N Yelland $^{4,5} \cdot$ Julie $A$ Owens ${ }^{1}$. \\ Jeffrey S Robinson ${ }^{1}$
}

Received: 8 June 2017 / Revised: 12 November 2017 / Accepted: 3 January 2018 / Published online: 30 January 2018

(c) The Author(s) 2018. This article is published with open access

\begin{abstract}
Background The immediate impact of providing an antenatal dietary intervention during pregnancy has been extensively studied, but little is known of the effects beyond the neonatal period. Our objective was to evaluate the effect of an antenatal dietary intervention in overweight or obese women on infant outcomes 6 months after birth.

Methods We conducted a follow up study of infants born to women who participated in the LIMIT trial during pregnancy. Live-born infants at 6-months of age, and whose mother provided consent to ongoing follow-up were eligible. The primary follow-up study endpoint was the incidence of infant BMI z-score $\geq 90$ th centile for infant sex and age. Secondary study outcomes included a range of infant anthropometric measures, neurodevelopment, general health, and infant feeding. Analyses used intention to treat principles according to the treatment group allocated in pregnancy. Missing data were imputed and analyses adjusted for maternal early pregnancy BMI, parity, study centre, socioeconomic status, age, and smoking status. Outcome assessors were blinded to the allocated treatment group.

Results A total of 1754 infants were assessed at age 6 months (Lifestyle Advice $n=869$; Standard Care $n=885$ ), representing $82.1 \%$ of the eligible sample $(n=2136)$. There were no statistically significant differences in the incidence of infant BMI z-score $\geq 90$ th centile for infants born to women in the Lifestyle Advice group, compared with the Standard Care group (Lifestyle Advice 233 (21.71\%) vs. Standard Care 233 (21.90\%); adjusted relative risk (aRR) 0.99; 95\% confidence interval 0.82 to $1.18 ; p=0.88$ ). There were no other effects on infant growth, adiposity, or neurodevelopment.

Conclusion Providing pregnant women who were overweight or obese with an antenatal dietary and lifestyle intervention did not alter 6-month infant growth and adiposity. Trial Registration: Australian and New Zealand Clinical Trials Registry (ACTRN12607000161426).
\end{abstract}

Jodie M Dodd

jodie.dodd@adelaide.edu.au

1 Discipline of Obstetrics \& Gynaecology, and The Robinson Research Institute, The University of Adelaide, Adelaide, SA, Australia

2 Women's and Babies Division, Department of Perinatal Medicine, The Women's and Children's Hospital, North Adelaide, SA, Australia

3 Women's and Babies Division; Department of Neonatal Medicine, The Women's and Children's Hospital, Adelaide, SA, Australia

4 School of Public Health, The University of Adelaide, Adelaide, SA, Australia

5 South Australian Health and Medical Research Institute, Adelaide, SA, Australia

\section{Introduction}

Across the globe, $>1.46$ billion adults [1], and 170 million children [2], are overweight or obese. It is well recognised that a woman's nutrition during pregnancy impacts pregnancy and birth outcomes, with the intra-uterine environment playing a key role in an individual's later health and disease [3]. Maternal obesity significantly predicts child and adult obesity in her offspring [4, 5], and associated cardiometabolic risk factors, including hypertension, hyperlipidaemia, diabetes, and cardiovascular disease [6-8]. Kitsantas and colleagues [9] report that maternal pre-gravid obesity increases the odds of pre-school obesity by a factor of 1.6 (OR 1.60; 95\% CI 1.26-2.03), while Rooney and colleagues [10] report a substantially greater increase in risk (RR 6.35; 95\% CI 3.28-12.30). Exposure to such an 
intra-uterine environment potentially creates a vicious cycle in which the propensity to obesity is perpetuated, with major adverse public health implications [11, 12], and implications for the health of successive generations [13].

There has been considerable research interest in the provision of antenatal dietary interventions during pregnancy to limit weight gain and improve pregnancy and birth outcomes for women and their infants. A comprehensive systematic review by Thangaratinam and colleagues [14] has identified numerous studies assessing dietary and lifestyle interventions in pregnancy, albeit mostly small in scope. While the findings reveal a relatively modest impact on weight gain [14], very little attention has been directed towards the ongoing follow-up of women and infants beyond the neonatal period to assess longer term outcomes.

To our knowledge, only three randomised trials involving the provision of an antenatal dietary intervention [1517] have conducted and reported findings of follow-up to 6 months after birth [18-20]. However, these studies have been limited by the relatively low rates of assessment [1820]. Furthermore, studies have focussed predominantly on measures of adiposity, and have not reported other clinically relevant infant outcomes $[18,20]$, or specifically reported infant outcomes among women who are overweight or obese [19].

We have previously shown that a comprehensive dietary and lifestyle intervention during pregnancy, in women who are overweight or obese, significantly improves both maternal diet and physical activity [21], is associated with an 18 and $41 \%$ relative reduction in the risk of high infant birth weight above 4 and $4.5 \mathrm{~kg}$ [22, 23], and was a cost neutral intervention [24]. On-going participant follow-up is required to assess the further impact of these findings on childhood outcomes. This manuscript reports the effect of the LIMIT antenatal dietary intervention, on 6-month infant outcomes.

\section{Methods}

The methods and primary clinical findings of the LIMIT randomised trial have been published [21-23], with the trial registered on the Australian and New Zealand Clinical Trials Registry (ACTRN12607000161426). Briefly, we conducted a multicentre randomised trial involving women with a singleton pregnancy, between $10^{+0}$ and $20^{+0}$ weeks' gestation, and body mass index $\geq 25.0 \mathrm{~kg} / \mathrm{m}^{2}$, who were randomised to either an antenatal dietary and lifestyle intervention (Lifestyle Advice Group) or standard antenatal care (Standard Care Group) [22].

Women in the Lifestyle Advice group received a comprehensive intervention over the course of their pregnancy that included a combination of dietary, exercise and behavioural strategies, delivered by a research dietician and trained research assistants [22]. Dietary information was consistent with current Australian standards [25], while physical activity advice focussed on the benefits of exercise in pregnancy [26]. Women were encouraged to set achievable goals for change, supported to make these lifestyle changes, to identify potential barriers and enablers to their implementation, and to self-monitor their progress [21, 22]. This information was delivered through two dedicated sessions with the research dietician (at trial entry, and 28 weeks) and trained research assistants (via telephone call at 22, 24, and 32 weeks, and a face-face visit at 36 weeks) $[21,22]$.

\section{Study design}

We conducted follow-up of infants born to women who participated in the LIMIT randomised trial 6-months after birth.

\section{Participants}

Women who participated in the LIMIT randomised trial, gave birth to a live infant, and who provided consent to the ongoing follow-up of their child, were eligible for inclusion. Women who suffered a stillbirth or neonatal death, or who withdrew from participation in ongoing follow-up were excluded.

\section{Follow-up schedule}

Each infant was assessed by a research assistant, blinded to the allocated treatment group. Eligible women were contacted to arrange a follow-up assessment of their child, either at the hospital of their birth, or if more convenient, for a research assistant to visit their home.

\section{Primary outcome}

The primary outcome was the incidence of infant BMI zscore $\geq 90$ th centile for infant age and sex at follow-up [27].

\section{Secondary outcomes}

Infant Anthropometric Measurements: We have an established and validated method of conducting anthropometric measurements in infants [28]. Information obtained included the infant's length, weight, weight-for-length, and anthropometric measurements (arm, thigh, waist and hip circumferences; biceps, triceps, sub-scapular, abdominal, supra-iliac and thigh skin-fold thickness). Research assistants used Harpenden skin-fold callipers to obtain skinfold thickness measurements, and received ongoing standardised 
training [29]. Weight, length, BMI, weight-for-length, and head circumference measures were converted to z-scores for age and gender, using WHO standards [27, 30].

Infant Neurodevelopment: The infant's primary caregiver was asked to complete a structured Ages and Stages Questionnaire (ASQ) [31], reporting five domains of development (communication, gross motor, fine motor, problem solving, and personal-social skills). Possible responses included Yes, Sometimes, or No, with a score in any one domain $>2$ SD below the mean considered indicative of the need for further assessment and when identified, the primary caregiver was advised to seek additional medical advice. The ASQ has been validated against the Bayley Scales [32], and in a paediatric population [33].

General health, health service utilisation, and quality of life: as assessed by questionnaire [34] completed by the infant's primary caregiver.

Infant Feeding: (breast, formula, or a combination of the two), as assessed by questionnaire completed by the infant's primary caregiver.

\section{Sample size}

The available sample size for follow-up assessment at 6months of age was predetermined by the LIMIT trial, which was powered on the primary outcome of large for gestational age, with 2212 women randomised [22]. Using data from the general Australian population, we anticipated a minimum incidence in the standard care group of BMI zscore $\geq 90$ th centile of approximately $25 \%$ [35]. A sample size of 1350 infants (75\% follow-up) would provide $80 \%$ power to detect at least a difference in the incidence of BMI z-score $\geq 90$ th centile of $6.4 \%$ (from 25 to $18.6 \%$; alpha 0.05 ). Detectable differences would range from $6.2 \%$ (with follow-up of $80 \%$ of children), to $6.7 \%$ (with follow-up of $70 \%$ of children; alpha 0.05 ; power $80 \%$ ). Small but relevant differences of $0.15-0.16$ standard deviations in secondary continuous outcomes could also be detected.

\section{Statistical analysis}

The analysis was conducted using intention to treat principles, according to the treatment group the woman was randomised to in pregnancy (Lifestyle Advice or Standard Care). Missing data were imputed for all randomised participants except those who had no live birth, who had an infant death, or who withdrew from the study and also withdrew permission to use data. Data were imputed separately by treatment group using the fully conditional specification (chained equations) method to create 100 complete datasets for analysis under the assumption that the data were missing at random (i.e., that "missingness" was independent of the values of the missing observations, conditional on observed data). In order to make the MAR assumption more plausible, a range of auxiliary variables, including stratification (centre, parity, BMI category) and adjustment variables (socioeconomic status, smoking, maternal age at consent, infant gender), along with infant birth measures (weight, length, circumferences and skinfold thickness measures), were included in the imputation model. The results of imputed analyses were compared with those from complete-case analyses, and further sensitivity analyses were also conducted for the primary outcome on the assumption that data were Missing Not At Random (MNAR). That is, analyses were conducted assuming that missing values had, firstly, a substantially greater incidence, and secondly, a substantially reduced incidence of z-scores $>90$ th percentile as compared with the observed data.

Both adjusted and unadjusted analyses were performed, with adjustment for variables used to stratify randomisation (maternal early pregnancy BMI category, parity, and centre of birth), in addition to maternal socioeconomic status, age, and smoking status. Infant outcomes other than z-scores were additionally adjusted for gender and actual age at assessment. For binary outcomes, relative risks with 95\% CI were estimated using log binomial regression. For continuous outcomes, differences in means with $95 \%$ CI were estimated using linear regression. Analyses were performed to test for effect modification by maternal BMI category. Statistical significance was set at $p<0.05$ (two-sided) with no adjustment for multiple comparisons, and all analyses followed a pre-specified plan.

\section{Ethics}

Approval was granted by the Women's and Children's Local Health Network Human Research and Ethics Committee at the Women's and Children's Hospital, the Central Northern Adelaide Health Service Ethics of Human Research Committee (Lyell McEwin Hospital) and the Flinders Clinical Research Ethics Committee (Flinders Medical Centre). All participants provided written informed consent to participate.

\section{Results}

Figure 1 outlines the flow of participants. A total of 2136 infants were eligible for the follow-up study and included in the analysis (96.6\% of the randomised sample). There were 1754 infants who were assessed at 6 months of age (Lifestyle Advice $n=869$; Standard Care $n=885$ ), representing $82.1 \%$ of the eligible sample. There were five deaths to 6 months of age (4 neonatal deaths as reported previously [22], and the death of one infant prior to 6 months of age attributable to sudden infant death syndrome). Table 1 


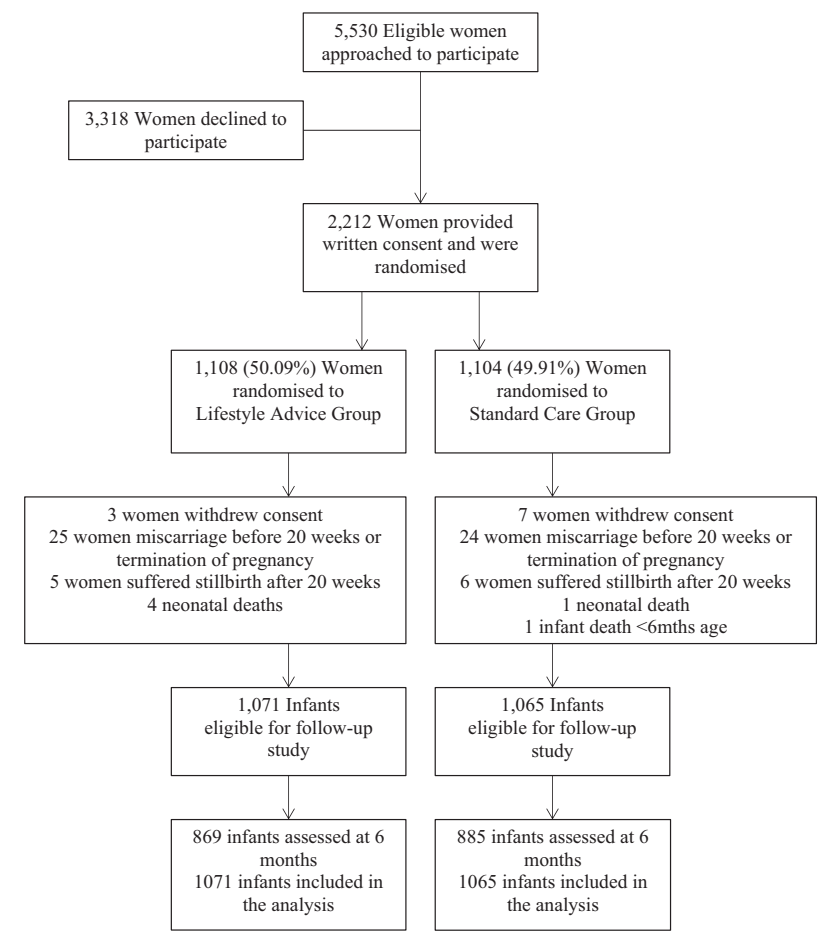

Fig. 1 Flow of participants

describes the baseline characteristics of the subset of eligible maternal participants, and are similar to the entire randomised cohort (data not shown) [22]. The median BMI of the cohort was $31.0 \mathrm{~kg} / \mathrm{m}^{2}$ (Inter Quartile Range (IQR) $27.8-35.6 \mathrm{~kg} / \mathrm{m}^{2}$ ), with $42.1 \%$ of women overweight, and $57.9 \%$ obese.

There were no statistically significant differences in the incidence of infant BMI z-score 290 th centile for infants born to women in the Lifestyle Advice group, as compared with those born to women in the Standard Care group (Lifestyle Advice 233 (21.71\%) vs. Standard Care 233 (21.90\%); adjusted relative risk aRR 0.99 ; $95 \%$ confidence interval (CI) 0.82 to $1.18 ; p=0.88$ ), or in infant BMI zscore $\geq 85$ th centile (Lifestyle Advice 299 (27.88\%) vs. Standard Care 303 (28.48\%); aRR 0.97; 95\% confidence interval (CI) 0.84 to $1.13 ; p=0.71$ ) (Table 2). Infants were not statistically significantly different between the two treatment groups with regards their weight (Lifestyle Advice $8.26 \mathrm{~kg}( \pm 1.33)$ vs. Standard Care $8.29 \mathrm{~kg}( \pm 1.33)$; adjusted mean difference (aMD) -0.05 ; $95 \% \mathrm{CI}-0.16$ to $0.06 ; p=0.38$ ), weight Z-score (Lifestyle Advice 0.30 $( \pm 1.13)$ vs. Standard Care $0.34( \pm 1.11)$; aMD $-0.04 ; 95 \%$ CI -0.14 to $0.06 ; p=0.43$ ), length (Lifestyle Advice 68.24 $\mathrm{cm}( \pm 3.76)$ vs. Standard Care $68.28 \mathrm{~cm}( \pm 4.13)$; aMD $-0.12 ; 95 \%$ CI -0.41 to $0.16 ; p=0.41)$, length Z-score (Lifestyle Advice $0.06( \pm 1.22)$ vs. Standard Care 0.11 $( \pm 1.28)$; aMD $-0.04 ; 95 \%$ CI -0.16 to $0.07 ; p=0.46)$, weight for length ratio (Lifestyle Advice $0.12( \pm 0.01)$ vs. Standard Care $0.12( \pm 0.01)$; aMD $-0.00 ; 95 \%$ CI -0.00 to
Table 1 Baseline characteristics for 6 month participants

\begin{tabular}{|c|c|c|c|}
\hline Characteristic & $\begin{array}{l}\text { Lifestyle } \\
\text { advice }(N= \\
1071)\end{array}$ & $\begin{array}{l}\text { Standard care } \\
(N=1065)\end{array}$ & $\begin{array}{l}\text { Total }(N= \\
\left.2136^{\mathrm{e}}\right)\end{array}$ \\
\hline $\begin{array}{l}\text { Maternal Age } \\
(\text { Years) })^{\mathrm{a}}\end{array}$ & $29.6(5.4)$ & $29.8(5.3)$ & $29.7(5.4)$ \\
\hline $\begin{array}{l}\text { Gestational Age at } \\
\text { Entry (Weeks) }\end{array}$ & $\begin{array}{l}14.3 \\
(12.0-17.0)\end{array}$ & $\begin{array}{l}14.3 \\
(12.1-17.1)\end{array}$ & $\begin{array}{l}14.3 \\
(12.0-17.4)\end{array}$ \\
\hline $\begin{array}{l}\text { Body Mass Index } \\
\left(\mathrm{kg} / \mathrm{m}^{2}\right)^{\mathrm{b}}\end{array}$ & $\begin{array}{l}31.2 \\
(28.0-35.8)\end{array}$ & $\begin{array}{l}31.0 \\
(27.7-35.4)\end{array}$ & $\begin{array}{l}31.0 \\
(27.8-35.6)\end{array}$ \\
\hline \multicolumn{4}{|c|}{ Body Mass Index Category ${ }^{\mathrm{c}}$} \\
\hline BMI 25.0-29.9 & $358(41.2)$ & $381(43.1)$ & $739(42.1)$ \\
\hline BMI 30.0-34.9 & $226(30.2)$ & $256(28.9)$ & $518(29.5)$ \\
\hline BMI 35.0-39.9 & $159(18.3)$ & $148(16.7)$ & $307(17.5)$ \\
\hline $\mathrm{BMI}>=40.0$ & $90(10.4)$ & $100(11.3)$ & $190(10.8)$ \\
\hline Weight $(\mathrm{kg})^{\mathrm{a}}$ & $88.3(16.6)$ & $88 \cdot 0(17.6)$ & $88.1(17.1)$ \\
\hline Height $(\mathrm{cm})^{\mathrm{a}}$ & $164.9(6.4)$ & $164 \cdot 7(6.5)$ & $164.8(6.5)$ \\
\hline \multicolumn{4}{|l|}{ Race $^{c}$} \\
\hline Caucasian & $790(90.9)$ & $802(90.6)$ & $1592(90.8)$ \\
\hline Asian & $19(2.2)$ & $31(3.5)$ & $50(2.9)$ \\
\hline Indian & $35(4.0)$ & $30(3.4)$ & $65(3.7)$ \\
\hline Other & $25(2.9)$ & $22(2.5)$ & $47(2.7)$ \\
\hline Smoker ${ }^{\mathrm{c}}$ & $98(11.3)$ & $91(10.3)$ & $189(10.8)$ \\
\hline Nulliparous $^{\mathrm{c}}$ & $359(41.3)$ & $353(39.9)$ & $712(40.6)$ \\
\hline \multicolumn{4}{|c|}{ Index of Socio-economic Disadvantage ${ }^{\mathrm{d}}$} \\
\hline Unknown & $1(0.1)$ & $1(0.1)$ & $2(0.1)$ \\
\hline $\begin{array}{l}\text { Quintile } 1 \text { (Most } \\
\text { Disadvantaged) }\end{array}$ & $256(29.5)$ & $251(28.4)$ & 507 (28.9) \\
\hline Quintile 2 & 214 (24.6) & $222(25.1)$ & $436(24.9)$ \\
\hline Quintile 3 & $139(16.0)$ & $134(15.1)$ & 273 (15.6) \\
\hline Quintile 4 & $122(14.0)$ & 141 (15.9) & $263(15.0)$ \\
\hline $\begin{array}{l}\text { Quintile } 5 \text { (Least } \\
\text { Disadvantaged) }\end{array}$ & $137(15.7)$ & $136(15.4)$ & 273 (15.6) \\
\hline
\end{tabular}

${ }^{a}$ mean and standard deviation

${ }^{\mathrm{b}}$ median and interquartile range

${ }^{c}$ number and $\%$

${ }^{\mathrm{d}}$ Socioeconomic index as measured by SEIFA IRSD

${ }^{\mathrm{e}}$ Includes all women whose infants were eligible for the 6 month follow-up study

$0.00 ; p=0.72$ ), or weight for length ratio Z-score (Lifestyle Advice $0.44( \pm 1.18)$ vs. Standard Care $0.48( \pm 1.14)$; aMD $-0.04 ; 95 \%$ CI -0.15 to $0.07 ; p=0.47)$. Body circumference and skin-fold thickness measures also did not differ significantly between infants born to women who received the antenatal intervention, and those who received standard care.

There were no statistically significant differences identified between infants born to women in the Lifestyle Advice group and those in the Standard Care group with regards to the overall Ages and Stages total score (Lifestyle Advice $262.47 \quad( \pm 34.92) \quad$ vs. Standard Care 258.72 


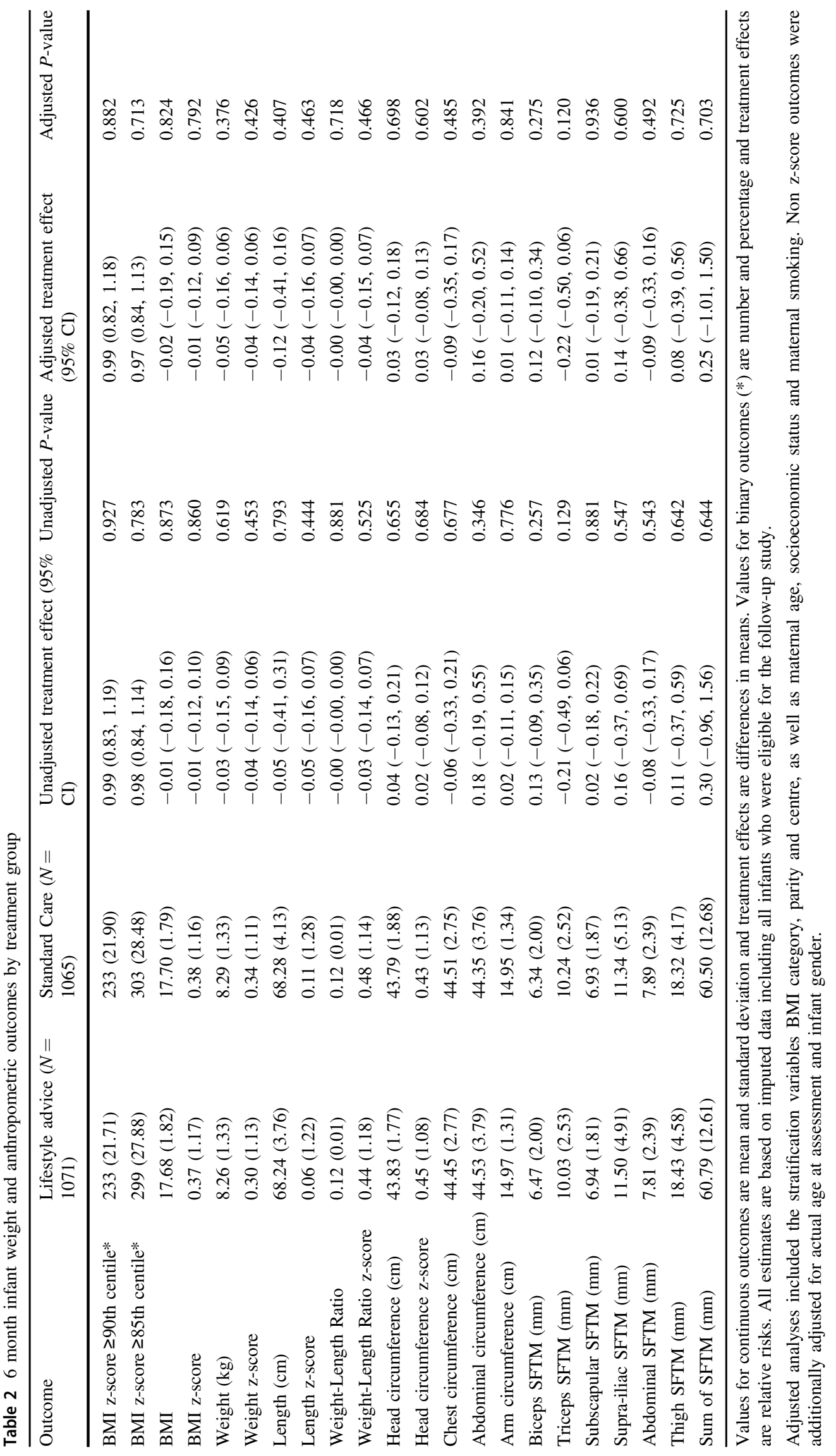


Table 36 month infant neurodevelopmental outcomes by treatment group, assessed by the Ages and Stages Questionnaire

\begin{tabular}{lllllll}
\hline Outcome & $\begin{array}{l}\text { Lifestyle advice } \\
(N=1071)\end{array}$ & $\begin{array}{l}\text { Standard care } \\
(N=1065)\end{array}$ & $\begin{array}{l}\text { Unadjusted treatment } \\
\text { effect }(95 \% \mathrm{CI})\end{array}$ & $\begin{array}{l}\text { Unadjusted } P \text { - } \\
\text { value }\end{array}$ & $\begin{array}{l}\text { Adjusted treatment } \\
\text { effect }(95 \% \text { CI })\end{array}$ & $\begin{array}{l}\text { Adjusted } P \text { - } \\
\text { value }\end{array}$ \\
\hline Communication domain & $51.30(9.03)$ & $50.95(9.63)$ & $0.35(-0.68,1.38)$ & 0.501 & $0.36(-0.67,1.38)$ & 0.493 \\
Gross motor domain & $53.35(10.05)$ & $52.74(10.84)$ & $0.61(-0.54,1.75)$ & 0.297 & $0.55(-0.59,1.69)$ & 0.344 \\
Fine motor domain & $52.25(10.52)$ & $51.20(10.74)$ & $1.05(-0.11,2.21)$ & 0.075 & $1.00(-0.13,2.14)$ & 0.082 \\
Problem solving domain & $53.60(9.55)$ & $52.86(9.15)$ & $0.74(-0.29,1.76)$ & 0.158 & $0.72(-0.31,1.74)$ & 0.170 \\
Social domain & $51.71(9.52)$ & $50.95(9.74)$ & $0.77(-0.34,1.87)$ & 0.173 & $0.69(-0.41,1.79)$ & 0.218 \\
Total score & $262.47(34.92)$ & $258.72(36.54)$ & $3.75(-0.13,7.63)$ & 0.058 & $3.53(-0.33,7.40)$ & 0.073 \\
$\begin{array}{l}\text { More than 1 score below } \\
\text { cut-off }\end{array}$ & $49(4.58)$ & $69(6.51)$ & $0.70(0.44,1.12)$ & 0.137 & $0.69(0.43,1.11)$ & 0.126 \\
\hline
\end{tabular}

Values are mean and standard deviation (or number and percentage), and treatment effects are differences in means (or relative risks) and are based on imputed data including all infants who were eligible for the follow-up study

Adjusted analyses included the stratification variables BMI category, parity and centre. Outcomes were additionally adjusted for maternal age, socioeconomic status and maternal smoking

( \pm 36.54$)$; aMD $3.53 ; 95 \% \mathrm{CI}-0.33$ to $7.40 ; p=0.07$ ), or in the proportion of infants identified with $>1$ domain below the cut-off (Lifestyle Advice 49 (4.58\%) vs. Standard Care 69 (6.51\%); aRR 0.69; 95\% CI 0.43 to $1.11 ; p=0.13$ ) (Table 3). Similarly, there were no statistically significant differences between the two groups with regards to the individual components of the Ages and Stages score (Table 3).

There were no significant differences between the two treatment groups with regards to infant feeding patterns, with $59.80 \%$ of infants still being breast fed at 6 months of age (Lifestyle Advice 324 (59.12\%) vs. Standard Care 347 (60.45\%); aRR $1.01 ; 95 \%$ CI 0.97 to $1.05 ; p=0.60$ ). Similarly, there were no significant differences identified with regards to general health or health service utilisation (Table 4).

There was no evidence to suggest that the effect of the antenatal intervention was modified by maternal BMI category for any of the reported outcomes (data not shown). In addition, results were compared to those of analyses using unimputed data, and (for the primary outcome) to the results of sensitivity analyses using data imputed under various MNAR assumptions. The results, in terms of both direction and magnitude of effect, were consistent across all of these analyses.

\section{Discussion}

Our findings indicate that provision of an antenatal dietary intervention for overweight or obese women was not associated with effects on infant growth, measures of adiposity, and neurodevelopmental outcomes at 6 months of age. There was no evidence to suggest that the effects of the intervention were modified by maternal BMI category.
Our findings represent the largest, most extensive, and most complete follow-up of infants to 6 months of age who were born to overweight and obese women following the conduct of the largest randomised trial to date evaluating the provision of a comprehensive antenatal dietary and lifestyle intervention. We have utilised robust methodology in terms of obtaining accurate measurement of early pregnancy weight, height, and BMI; detailed maternal dietary and physical activity history; and have delivered the antenatal intervention in a consistent manner to participants. Furthermore, we have utilised robust methodology to obtain anthropometric measures of the infants at 6 months of age, adhering to a standardised, research quality protocol.

A number of techniques have been described in the assessment of early infant body composition. Measurement of infant skinfold thickness $[36,37]$ and bio-impedance are considered reliable and relatively non-invasive methods of assessing fat distribution, both of which have been correlated with more invasive measures [36, 38-40]. Furthermore, percentage fat, as determined by skinfold thickness measurements has been validated against DXA calculations of fat mass in both infants and children [36, 41]. Although these more detailed body composition assessment tools may have yielded more accurate estimates of the relative proportions of adipose and lean tissue mass, they were not considered feasible for use in the large scale setting required for this follow-up study, and its associated practical and financial constraints.

Similarly, the use of the Ages and Stages questionnaire is considered a screening tool to identify infants at risk of neurodevelopmental delay [31]. While the use of a more sensitive test would provide more detailed and accurate estimates of early neurodevelopmental achievement, the ASQ has been validated against robust assessment tools [32], and in a paediatric population [33]. Again, the resources and intensive psychology training required to 


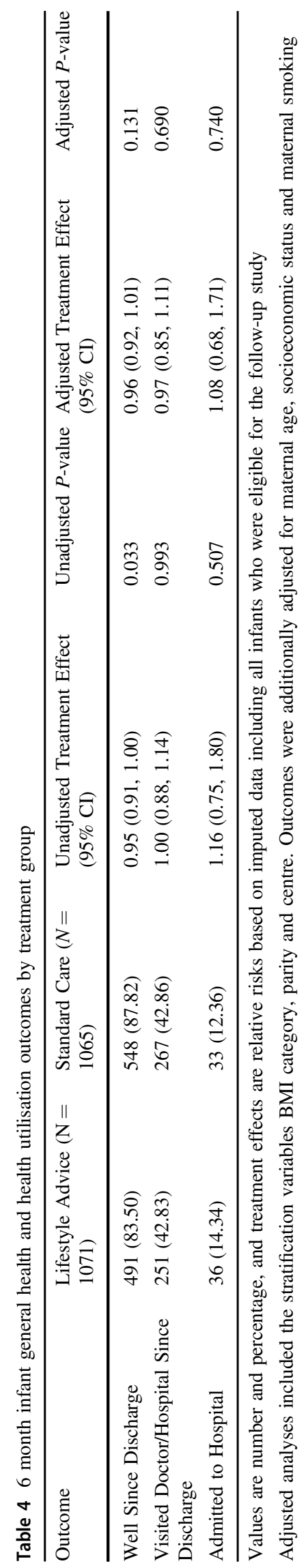

administer, for example, the more complex Bayley Scale, while generating more detailed information, was not considered feasible in our study population.

A potential limitation of our follow-up study is the risk of selection bias, with only $82 \%$ of the available cohort contributing data at 6-month follow-up assessments. We consider this risk, and the impact on the validity of our findings to be low. Characteristics of the women and infants for whom data was available and who participated in the 6month follow-up study were similar between the two randomised treatment groups, and similar to the full randomised cohort [22]. Further, analyses were based on all infants who were eligible for follow-up $(96.6 \%$ of those randomised) by using multiple imputation to address missing data for infants who were not assessed at 6 months.

Our findings indicate no evidence of an effect of a comprehensive dietary and lifestyle intervention provided during pregnancy for women who are overweight or obese, on measures of infant growth, adiposity, and neurodevelopment at 6-months of age. This is despite our previously published findings of significant but modest improvements in maternal diet and physical activity during pregnancy [21], and an 18 and $41 \%$ relative reduction in risk of infant birth weight above 4 [22] and $4.5 \mathrm{~kg}$, respectively [23]. While this may reflect evidence of a true lack of persisting effect of maternal dietary modification and birth weight on weight at 6-months of age, it may also be indicative that other factors are of relatively greater importance in driving early, ex-utero, infant growth and development.

Previous evidence on the longer-term effects of antenatal dietary and lifestyle interventions is limited. Vinter and colleagues [18] conducted a follow-up assessment of participants 6-months after birth, in which an antenatal dietary and lifestyle intervention was provided to overweight and obese women [15]. Although an assessment was conducted at 6 months post-partum involving $66 \%$ of participants [18], there have been no early infant outcomes reported to date. Follow-up of a smaller proportion of child participants at 2 to 3 years of age $[42,43]$ demonstrated no significant differences in the metabolic profile of children [42], or on measures of growth and adiposity [43].

The ROLO trial evaluated the effect of a low glycaemic index diet among women who had previously given birth to an infant with weight above $4 \mathrm{~kg}$ [16]. While not all women who participated in this trial were overweight or obese (mean BMI $26.8 \mathrm{~kg} / \mathrm{m}^{2}$ ), there was no evidence of an effect on infant birth weight [16]. Furthermore, follow-up of 280 infants (35\% of the randomised cohort) at 6-months of age demonstrated no evidence of an effect of the intervention on early infant measures of growth or adiposity [19].

The UPBEAT trial evaluated the effect of an antenatal dietary and lifestyle intervention among obese women, with no impact on infant birth weight demonstrated [17]. 
However, recently published findings from approximately $46 \%$ of eligible infants at 6 months of age (698 of 1522 eligible infants assessed) suggest a very small reduction in subscapular skinfold thickness measurement of $\sim 0.4 \mathrm{~mm}$ following provision of the antenatal intervention [20]. While statistically significant, the clinical significance of such a small difference is questionable, the findings also consistent with a chance occurrence, particularly as this was a secondary outcome, and no other statistically significant differences were identified between the treatment groups in infant BMI, abdominal circumference, or the remainder of infant anthropometric measures obtained.

There is emerging evidence, both from animal and human studies, of an association between maternal obesity and significantly higher risks of impaired offspring cognitive, motor and behavioural aspects of neurodevelopment [44-46]. Children born to women who are overweight or obese are more likely to be identified with moderate to severe cognitive, motor and global developmental delay at 3 years of age [46], as well as poorer academic achievement extending to 14 years of age [44, 45]. Autism spectrum disorders in childhood have also been observed and diagnosed more frequently among children born to women with metabolic conditions identified during pregnancy, including diabetes and obesity [47]. Our findings report, for the first time, the impact of an antenatal dietary intervention for women who are overweight or obese on early infant neurodevelopment. While we did not identify statistically or clinically significant differences in neurodevelopment at 6months of age using a reliable screening tool, ongoing follow-up of participants further into childhood will again be important to determine whether there are any potential benefits of improving maternal diet and physical activity during pregnancy on childhood neurodevelopment.

\section{Conclusions}

Antenatal dietary and lifestyle advice did not alter infant growth and adiposity at 6-months of age. Despite this, it remains important to continue to follow-up the children whose mothers participated in this intervention trial, particularly in view of the well recognised association between high-infant birth weight and subsequent childhood obesity [48], and the emerging associations between maternal obesity and impaired childhood neurodevelopmental function [46]. It will be valuable to utilise our clinical and biological databases to explore potential pathways whereby maternal obesity contributes to childhood outcomes, including obesity and impaired neurodevelopment.

Acknowledgements We are indebted to the 2212 women who participated in the LIMIT randomised trial, and to the 1754 parents and infants who contributed to the 6 month outcome data. The following persons in Adelaide, South Australia participated in the 6 month Follow-up of LIMIT Trial: Co-ordinating Team: JM Dodd, A Deussen, RM Grivell, L Yelland, L Moran, C Cramp, A Newman, L Kannieappan, M Kelsey, C Sheppard, D Post, M Cooney, A Webber, R Bartley, C Holst, K Robinson, S Zhang, V Ball. Statistical Analyses: J Louise and L Yelland. Writing Group: JM Dodd, A McPhee, A Deussen, L Yelland, J Louise, JA Owens, JS Robinson.

Funding This project was funded by intramural support from The University of Adelaide, Discipline of Obstetrics \& Gynaecology. JMD is supported through a NHMRC Practitioner Fellowship (ID 627005). The funder had no role in the study design, data collection, analysis, interpretation, or writing of the report.

\section{Compilance with ethical standards}

Conflict of interest The authors declare that they have no conflict of interest.

Open Access This article is licensed under a Creative Commons Attribution-NonCommercial-NoDerivatives 4.0 International License, which permits any non-commercial use, sharing, distribution and reproduction in any medium or format, as long as you give appropriate credit to the original author(s) and the source, and provide a link to the Creative Commons license. You do not have permission under this license to share adapted material derived from this article or parts of it. The images or other third party material in this article are included in the article's Creative Commons license, unless indicated otherwise in a credit line to the material. If material is not included in the article's Creative Commons license and your intended use is not permitted by statutory regulation or exceeds the permitted use, you will need to obtain permission directly from the copyright holder. To view a copy of this license, visit http://creativecommons.org/licenses/by-nc-nd/4.0/.

\section{References}

1. Finucane MM, Stevens GA, Cowan MJ, Danaei G, Lin JK, Paciorek CJ, et al. National, regional, and global trends in bodymass index since 1980: systematic analysis of health examination surveys and epidemiological studies with 960 country-years and 9.1 million participants. Lancet. 2011;377:557-67.

2. Lobstein T, Baur L, Uauy R. IASO International Obesity Task Force. Obesity in children and young people: a crisis in public health. Obes Rev.2004;5:4-104.

3. Barker DJP. Mothers, babies and disease in later life. 2nd Edition. London: Harcourt Brace \& Co; 1998.

4. Godfrey KM, Inskip HM, Hanson MA. The long-term effects of prenatal development on growth and metabolism. Semin Reprod Med. 2011;29:257-65.

5. Wells JC, Haroun D, Levene D, Darch T, Williams JE, Fewtrell MS. Prenatal and postnatal programming of body composition in obese children and adolescents: evidence from anthropometry, DXA and the 4-component model. Int J Obes. 2011;35:534-40.

6. Thornburg KL. The programming of cardiovascular disease. J Dev Orig Health Dis. 2015;6:366-76.

7. Fraser A, Tilling K, Macdonald-Wallis C, Sattar N, Brion MJ, Benfield L, et al. Association of maternal weight gain in pregnancy with offspring obesity and metabolic and vascular traits in childhood. Circulation. 2010;121:2557-64.

8. Mamun AA, Kinarivala M, O'Callaghan MJ, Williams GM, Najman JM, Callaway LK. Associations of excess weight gain during pregnancy with long-term maternal overweight and 
obesity: evidence from $21 \mathrm{y}$ postpartum follow-up. Am J Clin Nutr. 2010;91:1336-41.

9. Kitsantas P, Gaffney KF. Risk profiles for overweight/obesity among preschoolers. Early Hum Dev. 2010;86:563-8.

10. Rooney BL, Mathiasonm MA, Schauberger CW. Predictors of obesity in childhood, adolescence, and adulthood in a birth cohort. Matern Child Health J. 2011;15:1166-75.

11. Poston L. Gestational weight gain: influences on the long-term health of the child. Curr Opin Clin Nutr Metab Care. 2012;15:252-7.

12. O'Reilly JR, Reynolds RM. The risk of maternal obesity to the long-term health of the offspring. Clin Endocrinol. 2013;78:9-16.

13. Hannon TS, Rao G, Arsianian SA. Childhood obesity and type 2 diabetes mellitus. Pediatrics. 2005;116:473-80.

14. Thangaratinam S, Rogozinska E, Jolly K, Glinkowski S, Roseboom T, Tomlinson JW, et al. Effects of interventions in pregnancy on maternal weight and obstetric outcomes: meta-analysis of randomised evidence. Br Med J. 2012;344:e2088.

15. Vinter CA, Jensen DM, Ovesen P, Beck-Nielsen H, Jørgensen JS. The LiP (Lifestyle in Pregnancy) study: a randomized controlled trial of lifestyle intervention in 360 obese pregnant women. Diabetes Care. 2011;34:2502-7.

16. Walsh JM, McGowan CA, Mahony R, Foley ME, McAuliffe FM. Low glycaemic index diet in pregnancy to prevent macrosomia (ROLO study): randomised control trial. Br Med J. 2012;345: e5605.

17. Poston L, Bell R, Croker H, Flynn AC, Godfrey KM, Goff L, et al. Effect of a behavioural intervention in obese pregnant women (the UPBEAT study): a multicentre, randomised controlled trial. Lancet Diabetes Endocrinol. 2015;3:767-77.

18. Vinter CA, Jensen DM, Ovesen P, Beck-Nielsen H, Tanvig M, Lamont RF, et al. Postpartum weight retention and breastfeeding among obese women from the randomized controlled Lifestyle in Pregnancy (LiP) trial. Acta Obstet Gynecol Scand. 2014;93:794-801.

19. Horan MK, McGowan CA, Gibney ER, Byrne J, Donnelly JM, McAuliffe FM. Maternal nutrition and glycaemic index during pregnancy impacts on offspring adiposity at 6 months of age-analysis from the ROLO randomised controlled trial. Nutrients. 2016;8:E7.

20. Patel N, Godfrey KM, Pasupathy D, Levin J, Flynn AC, Hayes L, et al. Infant adiposity following a randomised controlled trial of a behavioural intervention in obese pregnancy. Int $\mathrm{J}$ Obes. 2017;41:1018-26.

21. Dodd JM, Cramp CS, Sui Z, Yelland LN, Deussen AR, Grivell $\mathrm{RM}$, et al. Effects of antenatal lifestyle advice for women who are overweight or obese on maternal diet and physical activity: the LIMIT randomised trial. BMC Med. 2014;12:161.

22. Dodd JM, Turnbull DA, McPhee AJ, Deussen AR, Grivell RM, Yelland LN, et al. Antenatal lifestyle advice for women who are overweight or obese: the LIMIT randomised trial. $\mathrm{Br}$ Med $\mathrm{J}$. 2014;348:g1285.

23. Dodd JM, McPhee AJ, Turnbull DA, Yelland LN, Deussen AR, Grivell RM, et al. The effect of antenatal lifestyle advice for women who are overweight or obese on neonatal health: the LIMIT randomised trial. BMC Med. 2014;12:163.

24. Dodd JM, Ahmed S, Karnon J, Umberger W, Deussen AR, Tran $\mathrm{T}$, et al. The economic costs and consequences of providing antenatal lifestyle advice for women who are overweight or obese: the LIMIT randomised trial. BMC Obes. 2015;11:14.

25. National Health and Medical Research Council. Australian Guide to Healthy Eating. National Health and Medical Research Council, Canberra; 2008.

26. Royal College of Obstetricians and Gynaecologists. Recreational exercise and pregnancy: information for you. London, RCOG Press; 2006.
27. World Health Organization. WHO Child Growth Standards: Length/height-for-age, weight-for-age, weight-for-length, weightfor-height, and body mass index-for-age. Methods and development. In: Organization WH, editor. Geneva: WHO; 2008.

28. Dodd JM, Deussen AR, Mohamad I, Rifas-Shiman SL, Yelland $\mathrm{LN}$, Louise $\mathrm{J}$, et al. The effect of antenatal lifestyle advice for women who are overweight or obese on secondary measures of neonatal body composition: the LIMIT randomised trial. BJOG. 2016;123:244-53.

29. Marfell-Jones M, Olds T, Stewart A, Carter L. International standards for anthropometric assessment. The International Society for the Advancement of Kinanthropometry, Potchefstroom, South Africa; 2006.

30. Freeman JV, Cole TJ, Chinn S, Jones PR, White EM, Preece MA. Cross sectional stature and weight reference curves for the UK, 1990. Arch Dis Child. 1995;73:17-24.

31. Bricker D, Squires J, Mounts L. Ages and stages questionnaire: 12 month: a parent completed child monitoring system. USA: Paul H Brookes Publishing Co; 1995.

32. Squires J, Potter L, Bricker D. The ASQ user's guide for the ages and stages questionnaires: a parent-completed, child-monitoring system. Baltimore: Paul H Brookes Publishing Company; 1995.

33. Skellern CY, Rogers Y, O'Callaghan MJ. A parent-completed developmental questionnaire: follow-up of ex-premature infants. J Paediatr Child Health. 2001;37:125-9.

34. Crowther CA, Doyle LW, Haslam RR, Hiller JE, Harding JE, Robinson JS, et al. Outcomes at 2 years of age after repeat doses of antenatal corticosteroids. N Engl J Med. 2007;357:1179-89.

35. The National Obesity Taskforce. Healthy Weight 2008: Australia's future-The national action agenda for children and young people and their families. In: Ageing ACDoHa editor. Canberra: Australian Commonwealth Deaprtment of Communications, Information Technology and the Arts; 2008.

36. Schmelzle HR, Fusch C. Body fat in neonates and young infants: validation of skinfold thickness versus dual-energy X-ray absorptiometry. Am J Clin Nutr. 2002;76:1096-1100.

37. Gillman MW, Rich-Edwards JW, Huh S, Mujzoub JA, Oken E, Taveras EM, et al. Maternal corticotrophin-releasing hormone levels during pregnancy and offspring adiposity. Obesity. 2006; $14: 1647-53$.

38. Lingwood BE, Dodrill P, Davies PS, Callaway L, Colditz P. Measurement of infant body composition using the peapod and bioimpedance analysis. J Paed Child Health. 2008;44:A99. Suppl 1

39. Thomson R, Brinkworth GD, Buckley JD, Noakes M, Clifton PM. Good agreement between bioelectrical impedance and dual energy $\mathrm{X}$-ray absorptiometry for estimating changes in body composition during weight loss in overweight young women. Clin Nutr. 2007;26:771-7.

40. Volgyi E, Tylavsky FA, Lyytikainen A, Suominen H, Alen M, Cheng S. Assessing body composition with DXA and bioimpedance: effects of obesity, physical activity and age. Obesity. 2008;16:700-5.

41. Godang K, Qvigstad E, Voldner N, Isaksen GA, Frøslie KF, Nøtthellen J, et al. Assessing body composition in healthy newborn infants: reliability of dual-energy $\mathrm{x}$-ray absorptiometry. $\mathrm{J}$ Clin Densitom. 2010;13:151-60.

42. Tanvig M, Vinter CA, Jørgensen JS, Wehberg S, Ovesen PG, Beck-Nielsen $\mathrm{H}$, et al. Effects of lifestyle intervention in pregnancy and anthropometrics at birth on offspring metabolic profile at 2.8 years: results from the Lifestyle in Pregnancy and Offspring (LiPO) study. J Clin Endocrinol Metab. 2015;100:175-83.

43. Tanvig M, Vinter CA, Jørgensen JS, Wehberg S, Ovesen PG, Lamont RF, et al. Anthropometrics and body composition by dual energy X-ray in children of obese women: a follow-up of a 
randomized controlled trial (the Lifestyle in Pregnancy and Offspring [LiPO] study). PLoS ONE. 2014;9:e89590.

44. Pugh SJ, Richardson GA, Hutcheon JA, Himes KP, Brooks MM, Day NL, et al. Maternal obesity and excessive gestational weight gain are associated with components of child cognition. J Nutr. 2015;145:2562-9.

45. Pugh SJ, Hutcheon JA, Richardson GA, Brooks MM, Himes KP, Day NL, et al. Child academic achievement in association with pre-pregnancy obesity and gestational weight gain. J Epidemiol Community Health. 2016;70:534-40.
46. O'Connor Duffany K, McVeigh KH, Kershaw TS, Lipkind HS, Ickovics JR. Maternal obesity: risks for developmental delays in early childhood. Matern Child Health J. 2016;20:219-30.

47. Krakowiak P, Walker CK, Bremer AA, Baker AS, Ozonoff S, Hansen RL, et al. Maternal metabolic conditions and risk for autism and other neurodevelopmental disorders. Pediatrics. 2012;129:e1121-e1128.

48. Cunningham SA, Kramer MR, Narayan KM. Incidence of childhood obesity in the United States. N Engl J Med. 2014;370:403-11. 